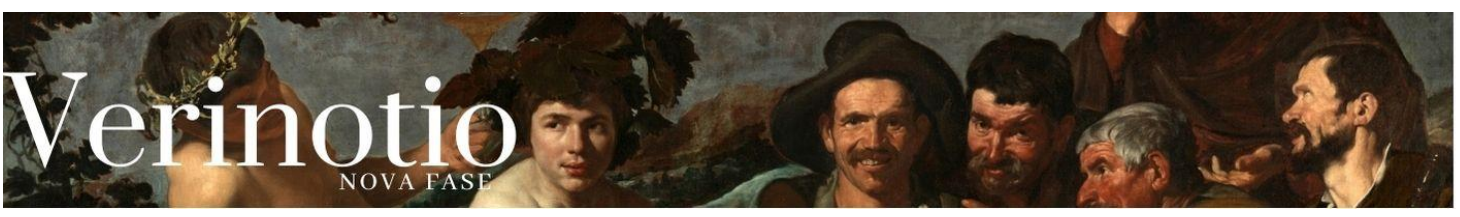

\title{
Em memória de Mario Duayer
}

\section{Paulo Henrique Furtado de Araujo*}

Resumo: $O$ artigo realiza uma homenagem póstuma a Mario Duayer, cuja vida foi ceifada pela pandemia do COVID-19 no início do ano de 2021. Trata-se de um relato pessoal da convivência com Mario Duayer, do resgate de sua importância na formação de uma geração de pesquisadores, professores e lutadores sociais que têm no marxismo o horizonte de teoria e práxis. Oferece um resumo da produção teórica de Mario Duayer, enfatizando os últimos dez anos de sua produção e apresenta as linhas gerais de seu esforço último por aproximar teoricamente a Ontologia de Lukács e a reinterpretação do pensamento de Marx, proposta por Moishe Postone.

Palavras-chave: Mario Duayer; Marx; Lukács; Postone; homenagem.

\begin{abstract}
The article pays a posthumous tribute to Mario Duayer, whose life was cut short by the COVID-19 pandemic at the beginning of 2021 . It is a personal account of my closeness and familiarity to Mario Duayer, of the rescue of his importance in the formation of a generation of researchers, teachers and social activists who have in Marxism the horizon of theory and praxis. It offers a summary of Mario Duayer's theoretical production, emphasizing the last ten years of his production and presents the general lines of his last effort to theoretically approximate Lukács' Ontology and the reinterpretation of Marx's theory, proposed by Moishe Postone.
\end{abstract}

Keywords: Mario Duayer; Marx; Lukács; Postone; homage.

|

No dia 16 de janeiro de 2021 perdemos Mario Duayer para a pandemia que assola o planeta e que, até esse momento em que escrevo, ceifou a vida de 514.092 brasileiros. As ações deliberadas e conscientes, tomadas pelo (des)governo milicianoempresarial-militar, que ocupa o núcleo central do poder executivo brasileiro e que miram a facilitação do contágio viral, explicam essa tragédia. Essa pandemia é mais uma manifestação fenomênica da crise estrutural produzida pela contradição fundamental da sociedade do capital (entre valor de uso e valor) e que tem por correlato a produção de uma massa do povo permanentemente excluída da possibilidade da produção do laço social (valor) que garante o pertencimento de cada singularidade humana à comunidade na qual está inserida - desemprego permanente. Acrescente-se a atual crise ambiental que, tudo indica, já é irreversível, e temos sinais claros do esgotamento das possibilidades civilizatórias do capitalismo. Tais manifestações evidentes do aprofundamento da barbárie são o arrimo para o

\footnotetext{
* Doutor pela UFRRJ e professor da Faculdade de Economia da UFF, do PPGE-UFF, Coordenador do GEPOC-UFF e membro do NIEP-MARX-UFF. E-mail: phfaraujo@id.uff.br.
} 
desenvolvimento das formas ideológicas, as mais reacionárias e que passam a dominar o complexo da política: fascismo, nazismo, racismo etc.

Mario Duayer nos deixou nesse momento crucial para os rumos do devir humano do ser humano e nos privou das análises, refinadas e precisas, que tanto nos ajudavam na elucidação de complexos de problemas que poucos revolucionários marxistas na atualidade abordam.

Ofereço aos leitores um singelo relato de minha convivência com Mario em que procuro destacar o seu compromisso teórico e prático com a emancipação humana e tento indicar a dimensão da perda humana e intelectual que o seu desaparecimento acarretou.

II

Encontrei Mario pela primeira vez em janeiro ou fevereiro do distante ano de 1989. Era o encontro de apresentação da primeira turma selecionada, a partir das provas da ANPEC, para o Mestrado em Economia da UFF. Meu interesse era o estudo de Marx e, quando da seleção para o mestrado, descobri que na Economia da UFF havia um núcleo de professores marxistas. Minha escolha pelo programa foi natural e, nesse primeiro encontro, além de Mario, conheci Victor Hugo Klagsbrunn. Os dois professores eram, naquele momento, os marxistas do Programa, e eu, naturalmente, me aproximei deles. Victor Hugo veio a ser meu orientador oficial da dissertação de mestrado, e Mario um orientador informal. No primeiro semestre do curso, Mario oferecia uma disciplina obrigatória que era de leitura do Livro 1 de O Capital - texto que eu já conhecia da graduação - com uma bibliografia complementar que era inovadora naquele momento. Mario trazia, sempre que possível e adequado, as contribuições de Lukács colhidas em Para uma ontologia do Ser Social. Isso num período em que só dispúnhamos de dois capítulos da obra de Lukács vertidos para o português por Carlos Nelson Coutinho - $A$ falsa e a verdadeira ontologia de Hegel e Os princípios ontológicos fundamentais de Marx. Mario complementava suas intervenções em nossas aulas com referências a textos de José Chasin e István Mészáros. ${ }^{1}$ Tal abordagem provocou profunda impressão em toda turma, e um grupo de alunos demonstrou interesse em aprofundar a leitura da Ontologia de Lukács. A partir desse movimento, Mario ofereceu por mais três semestres disciplinas optativas

\footnotetext{
${ }^{1}$ Com destaque para os artigos publicados na Revista Ensaio e, posteriormente, na Revista Ad Hominen.
} 
que funcionaram como grupos de estudos. O que já revelava uma característica permanente do modo de ser de Mario: a preocupação em aprender coletivamente e em avançar no conhecimento coletivamente. Elucidando e auxiliando, de modo rigoroso, cada aluno em suas dúvidas e dificuldades.

Nesse período, a pesquisa de Mario tinha por foco as questões do método. Mario se ocupava, com grande afinco, em elucidar os problemas relacionados à teoria do conhecimento (gnosiologia e epistemologia) e em esclarecer as necessárias ligações entre gnosiologia/epistemologia e a ontologia materialista do ser social. Sua pesquisa nesse campo se estende de 1988/89 até 2004/2005 e resultou em uma grande quantidade de artigos científicos e capítulos de livros publicados e que ainda hoje são referência para o debate na área. Aqui, é preciso mencionar outra característica de Mario: a permanente busca por interlocutores teóricos no plano nacional e internacional. Disso decorre a descoberta das contribuições de Roy Bhaskar e os autores do campo do Realismo Crítico e a consequente incorporação crítica dessas abordagens em suas reflexões teóricas a respeito da teoria do conhecimento, que se mantinham no campo do marxismo e articulavam esses autores recém-descobertos com as contribuições do próprio Marx, de Lukács, Mészáros, Chasin etc.

No intervalo de tempo referido, Mario, ao lado de sua elaboração teórica, participa ativamente (e em parceria com Victor Hugo Klagsbrunn) do processo de organização e fundação da Sociedade Brasileira de Economia Política (SEP). ${ }^{2}$ A SEP, ao longo dos anos de sua existência, transforma-se na principal entidade brasileira (sustentada por pessoas físicas) dos economistas heterodoxos (os que não aceitam o mainstream da teoria econômica como chave explicativa da sociedade e da economia capitalista) e dos economistas marxistas em particular; sendo hoje referência continental e mundial no campo da teoria econômica crítica e heterodoxa.

Alguns anos após a conclusão do meu mestrado, fui aprovado em concurso público para o cargo de professor de Teoria Econômica do Departamento de Economia da Universidade Federal Rural do Rio de Janeiro (UFRRJ), em Seropédica - município um pouco distante de Niterói. Essa contingência e as circunstâncias da vida acabaram por me afastar do convívio pessoal e intelectual com Mario. Ainda que nos víssemos em alguns momentos festivos ao longo dos anos, foi somente no ano de 2009 que

\footnotetext{
${ }^{2}$ A SEP foi fundada em 1996 na UFF, em Niterói, no Primeiro Encontro Nacional de Economia Clássica e Política.
} 
pude retomar aquele convívio, ao ser aprovado em novo concurso público, agora para professor de Pensamento Econômico da Faculdade de Economia da UFF. Em meu retorno à UFF, tive a felicidade de ser apresentado ao círculo de professores, alunos, amigos e colegas que privavam da convivência com Mário. Para não cometer injustiças, não citarei nenhum dos amigos em particular, mas registro que o Núcleo Interdisciplinar de Estudos e Pesquisas sobre Marx e o Marxismo da UFF - NIEP-MARXUFF - era o centro gravitacional de todos nós. O NIEP surge em 2003 e congrega professores, pesquisadores e alunos de diversas unidades da UFF (Economia, História, Educação, Serviço Social, Sociologia, Arquitetura etc.). Todos tendo em comum o pensamento de Marx enquanto eixo articulador de seus trabalhos de ensino, pesquisa e extensão. Mario foi um dos fundadores e organizadores do NIEP - que hoje é uma referência no campo do marxismo tanto no Brasil como internacionalmente.

Quando da retomada da interlocução com Mario, fui apresentado por ele a um $^{3}$ autor desconhecido no debate brasileiro, naquele momento, e que Mario havia descoberto em um de seus pós-doutorados: Moishe Postone. Nessa altura, Mario já se afastava dos estudos sobre metodologia e passava a se dedicar às questões apresentadas por Postone. Uma vez, indagado sobre esse afastamento por um amigo em comum, ${ }^{4}$ Mario respondeu que ele já tinha obtido autoesclarecimento, o que o levara a estudar outros assuntos. Postone, eu arriscaria dizer, é um autor incontornável para a reconstrução do marxismo enquanto ciência e ideologia que aponta para a humanização do ser humano. Ainda assim, é um autor envolto em polêmicas e malentendidos. O meu primeiro contato com a obra principal do autor (Tempo, Trabalho e Dominação Social) me levou a uma rápida rejeição. Comentei com Mario de que se tratava de um autor anti-marxista. Mario, com paciência e generosidade, se dispôs a demonstrar que não se tratava disso, muito pelo contrário, o autor oferecia a possibilidade de uma leitura de Marx que resgatava a radicalidade de sua crítica à sociedade do capital.

Postone esclarecia, explicava Mario, que para Marx a sociedade do capital é moldada pelo valor que tem por substância o trabalho abstrato. Capital que é

\footnotetext{
${ }^{3}$ Nesse período, eu dividia gabinete de trabalho, na Faculdade de Economia da UFF, com João Leonardo Medeiros (dentre outros amigos), que gentilmente me enviou cópias dos artigos e livro de Postone e que se dispôs a dialogar a respeito das ideias do autor. Aqui registro meu carinho e agradecimento a João.

${ }^{4}$ Faço referência a Natan Oliveira.
} 
contradição em processo, que é valor em expansão, em verdade, é trabalho abstrato se expandido sob a forma de mercadoria e dinheiro (D-M-D') e abarcando e modelando a totalidade objetiva e subjetiva do mundo humano na sociedade em que domina $o$ modo de produção capitalista. Não por outro motivo, Marx inicia a exposição de sua obra magna a partir da análise da mercadoria iluminando as categorias valor de uso e valor para, em seguida, demonstrar que valor de troca é a forma de manifestação do valor. De imediato, nos diz que a riqueza da sociedade capitalista aparece (fenomenicamente) como uma coleção de mercadorias (valores de uso), indicando que há uma riqueza especificamente capitalista - valor. No mesmo movimento, apresenta a concorrência capitalista como parte crucial da valorização do valor, ao abordar o aumento da força produtiva do trabalho no caso da adoção de teares mecânicos pela indústria têxtil inglesa no século XIX. O aumento da produtividade altera o valor por unidade produzida de mercadoria sem alterar o valor total produzido e devém pelo aumento da mecanização do processo de trabalho - que Marx irá elucidar, em particular, no capítulo 23 do Livro 1 de 0 Capital, como aumento da composição orgânica do capital. Marx estabelece, segundo Postone, os marcos gerais da própria dinâmica do capital: a obrigatoriedade de produzir com mais eficiência, maior produtividade, de modo que a lógica do capital engendra uma dialética da transformação e reconstituição do nível de produtividade e do tempo de trabalho socialmente necessário - que Postone irá chamar de Efeito Esteira.

Ainda no primeiro capítulo do Livro 1 de 0 Capital, Marx demonstra, assinala Postone, que valor é categoria mediadora social. Dito de outro modo: os laços sociais entre os seres humanos na sociedade do capital são indiretos mediados pela mercadoria que é valor e valor de uso ao mesmo tempo. Segue afirmando que o trabalho determinado por mercadoria possui um duplo caráter (produtor de valor de uso e de valor) e tem que objetivar a própria relação social sob a forma de mercadoria. A relação social é coisificada e exteriorizada e, imediatamente, propicia a relação social direta entre as coisas produzidas pelos humanos sob a forma de mercadorias. Por consequência lógica, o valor, sob a forma de mercadoria e dinheiro, adquire vida própria e passa a dominar a vida dos produtores. Consuma-se a inversão sujeito-objeto e o humano devém objeto de sua objetivação - para Marx essa é a forma específica da dominação capitalista: dominação abstrata do valor. Como o valor é quantificado pelo tempo de trabalho socialmente necessário, estamos diante de uma dominação temporal. Em seu nível mais crucial, essa é a dominação específica da sociedade do 
capital.

Postone, com isso, sustenta que em Marx de O Capital, a subjetividade do ser humano é balizada pelo constrangimento lógico do valor em expansão. O fetiche da mercadoria e a dominação abstrata são momentos distintivos da formação de cada subjetividade. Ainda assim, segundo o autor, não se trata da constituição de algum determinismo, mecanicismo ou estruturalismo. $\mathrm{O}$ agir humano ocorre, as escolhas e o livre-arbítrio operam, ainda que no interior dos limites da referida lógica. Tal constatação indica que a crítica à sociedade do capital é possível e que a emancipação humana da dominação do valor é uma tarefa viável.

A crítica de Marx, para Postone, caracteriza-se, podemos agora explicitar, por ser uma crítica do trabalho no capitalismo e não uma crítica do capitalismo do ponto de vista do trabalho. Essa inversão produz toda uma série de consequências para o pensamento marxista - por exemplo, coloca a questão do sujeito da história. No capítulo 4 do Livro 1 de 0 Capital, o valor, que assume a forma de mercadoria e forma dinheiro mantendo-se inalterável qualitativamente como substância (trabalho abstrato) e se ampliando quantitativamente $\left(D^{\prime}=D+\Delta D\right)$, vem a ser capital - , sujeito automático do processo de autovalorização, ou seja, sujeito-objeto idêntico. Um sujeito abstrato, sem consciência, com evidente tendência totalizadora - pois todos os aspectos da vida social humana passam a ser dominados por esse constrangimento lógico - e produtor de uma dinâmica histórica endógena à sociedade do capital que aponta para a permanente transformação e reconstituição dos padrões temporais da produção do valor e das configurações assumidas pelas estruturas sociais pseudo-objetivas plasmadas por ele. Um sujeito abstrato, que só engendra um tempo histórico de perpétua produção de valor ampliado, tem por legado a interdição do futuro, o apagamento de todo o passado do gênero humano e a oferta de uma permanente presentificação: a omnilateralidade do ser humano, na sociedade do capital, é mutilada, o humano é transformado em aleijão, unilateralizado, esvaziado enquanto mero produtor de valor e animalizado na práxis humana que inaugura, ontologicamente, o longo processo de explicitação do que há de humano no ser humano.

Abordar o sujeito da história requer que se trate das classes sociais, dado que no marxismo tradicional, o proletariado é identificado como o sujeito da história, da revolução e da emancipação. Aqui não é o lugar para a explicitação das posições envolvidas no debate e, portanto, limito-me a abordar a compreensão que Mario 
advogava. O proletário, para Marx de $O$ Capital, é o trabalhador produtivo e ser produtivo, nesse caso, é valorizar valor para o capitalista. Desse modo, as classes sociais abordadas nas primeiras seções do Livro 1 de $O$ Capital (burgueses e proletários) surgem determinadas, em seu nível mais essencial, pelo valor em expansão. $O$ valor tem prioridade ontológica e é momento determinante em relação as classes, e essas se apresentam em determinação reflexiva. De tal modo que a mera condição de ser proletário não constitui, per se, uma consciência emancipadora, nem mesmo como instinto de classe ou dynamei. Ao longo dos capítulos da referida obra, Marx demonstra que as lutas de classe do cotidiano, engendradas pela lógica do valor, permitem ao proletariado em luta arrancar direitos da burguesia (por exemplo, limitação da jornada de trabalho). Uma vez vitoriosas, essas lutas do cotidiano permitem que o proletário venda sua mercadoria (força de trabalho) por um quantum maior de valor sob a forma de um salário mais elevado. O que irá garantir um maior consumo de mercadorias, melhorias na qualidade de vida das famílias e, desse modo, um aprofundamento do aprisionamento do proletário nos grilhões da dominação abstrata do valor.

As lutas do cotidiano, sob circunstâncias específicas e favoráveis, podem favorecer o surgimento de momentos catárticos em que a consciência do produtor é acessada por um conjunto de valores ético-morais que o empurram para além da sociabilidade do valor. Decorre, acrescenta Postone, que ao lado das lutas de classe do cotidiano é possível e necessária a constituição de lutas emancipatórias ou revolucionárias. Tais lutas podem e devem abarcar as questões de raça, gênero, ecológica etc. articulando a busca por formas de sociabilidade manifestas entre os humanos e que possam substituir os laços sociais indiretos arrimados no valor.

Para arrematar o resumo aqui esboçado, e partindo da reconstrução da teoria de Marx sugerida por Postone, apresento, em traços muito lassos, uma leitura possível para o problema atual da redução numérica do proletariado e do papel do proletariado no processo de emancipação humana do valor. Pouco acima, registrei que Marx trata da concorrência capitalista como corolário necessário do valor em expansão que constitui, de modo inexorável, uma tendência ao aumento da composição orgânica do capital ou a substituição física do trabalho vivo pelo trabalho morto (sob a forma de maquinaria) com a redução mais acentuada no valor da força de trabalho (capital variável) em comparação como valor do capital constante (máquinas, equipamentos e matérias-primas). No capítulo 23 do Livro 1 de $O$ Capital, Marx acrescenta que a 
acumulação capitalista produz incessantemente uma superpopulação trabalhadora que é supérflua para as condições médias da própria acumulação. Ao analisar as diferentes formas de existência da superpopulação relativa (flutuante, latente, estagnada e no pauperismo), Marx conclui que a lei geral da acumulação capitalista aponta para o fato de que quanto maior for o aumento da produção da riqueza social, do volume do capital em funcionamento e da vitalidade do seu crescimento, maior será a superpopulação supérflua (ou exército industrial de reserva); e tanto maior será o pauperismo - uma proporção cada vez maior do proletariado que perde seus laços com a classe social e a possibilidade de permanecer capaz de produzir o laço social (valor). Essa tendência é o que pode explicar o desenlace que Marx oferece, ao final do capítulo 24 do Livro 1 de 0 Capital, ao dizer que a tarefa de expropriar os expropriadores, na sociedade do capital, é da massa do povo (Volksmasse). E, em nota de rodapé, remeter o leitor para uma passagem do Manifesto do Partido Comunista em que a massa do povo é sinônimo de proletário. Considerando que ao escrever o Manifesto Marx ainda não havia realizado a ruptura ontológica no âmbito da economia política e, portanto, ainda não havia constituído sua teoria do valor, podemos inferir que ser proletário, no referido texto, é sinônimo de miserável, pauperizado, oprimido, deserdado, humilhado etc. Após o giro ontológico e a instauração de sua teoria do valor, Marx compreende que ser proletário é uma determinação do valor em expansão e que a tendência geral da acumulação capitalista não é a do fortalecimento do proletário que seria portador de um instinto (metafísico?) emancipador. Ao contrário, a tendência é para a perda de peso e importância do trabalhador produtivo e o desenvolvimento do pauperismo constituindo uma massa de deserdados, a massa do povo. A essa massa cabe a tarefa de realizar a expropriação dos expropriadores e a organização da vida social em laços sociais manifestos, para além do valor.

Para não prolongar por demais esse excurso que já se demonstra excessivo, concluo o esboço assinalando que essa chave de leitura exige dos marxistas a reinterpretação das formas políticas de organização, das táticas e estratégias a serem adotadas pelos revolucionários e, o mais importante, a descoberta no hic et nunc dos caminhos para o aprendizado, constituição e generalização de laços sociais assentados nos valores antípodas aos valores ético-morais do capital. A simples enumeração das tarefas e desafios já indica o quanto a reinterpretação de Marx oferecida por Postone é polêmica e incômoda para a tradicional figuração de mundo no campo do marxismo. 
III

Mario, no ano de 2011, aposentou-se como Professor Titular da Faculdade de Economia da UFF e passou a ser Professor Visitante no Programa de Pós-Graduação em Serviço Social da UERJ (Universidade do Estado do Rio de Janeiro). Naturalmente, ocorreu um certo distanciamento do dia a dia da UFF, e Mario, em 2012, organizou um novo grupo de estudos e pesquisas, o GEPOC (Grupo de Estudos e Pesquisas em Ontologia Crítica), retomando o nome de um outro grupo que ele ajudara a criar quando de sua estadia como Professor Visitante no curso de Pós-Graduação em Sociologia Política na UFSC (Universidade Federal de Santa Catarina) nos anos de 2006-2007. O GEPOC, em seu início, reunia pesquisadores da própria UERJ, todavia, rapidamente foram sendo incorporados professores e alunos de outras instituições (UFF, UFRJ). No ano de 2016, com o fim do vínculo de Mario com a UERJ, o grupo passa a se reunir no campus da UFF e modifica seu nome para GEPOC-UFF.

Nesse período, explicita-se o veio principal da pesquisa que Mario irá desenvolver até o final de sua vida: as proximidades e contradições entre a Ontologia de Lukács e a reconstrução da teoria de Marx ofertada por Postone. Para alguém que conheça um pouco os dois autores e suas contribuições teóricas, pode parecer, de imediato, que se trata de uma tarefa impossível. Postone é explícito ao negar a validade de qualquer ontologia, que ele associa a metafísica (em pleno acordo com o entendimento de Adorno). Mario percebeu que Postone, sem saber, instaura uma crítica ontológica ao marxismo tradicional e, ao mesmo tempo, possuía uma compreensão da teoria do valor que era adequada ao constructo teórico oferecido por Lukács em sua obra final. O primeiro desafio a ser enfrentado era como sustentar que o trabalho não era emancipador por si. Ou ainda, diferenciar o trabalho universal/geral, fundante do ser social, motor do processo de afastamento da barreira natural e o início da constituição da substância do ser social e de suas formas de manifestação fenomênicas, do trabalho determinado por mercadoria que unilateraliza o ser humano e se instaura como o centro, o eixo estruturante, e da sociedade moderna. A essa tarefa Mario se dedicou e fez avançar a compreensão sobre as diferenças entre trabalho enquanto fundante do ser social e o trabalho que é central na sociedade do capital.

Ao mesmo tempo não lhe escapava que as leituras desses autores, para se tornarem ideologias de fato, precisavam não apenas apresentar respostas para os problemas contemporâneos do processo de acumulação de capital, mas, 
sincronicamente a essas respostas, se apossar da consciência da massa do povo. Tal perspectiva levou Mario a voltar a estudar, nas reuniões do GEPOC-UFF, a obra principal de Postone (Tempo, Trabalho e Dominação Socia), os livros 2 e 3 de O Capital (também nas reuniões do GEPOC-UFF) e os capítulos $A$ Reprodução, $O$ ldeal e a Ideologia e O Estranhamento de Para uma Ontologia do Ser Social (na preparação das aulas das turmas que dividíamos no PPGE-UFF) - esse esforço foi realizado ao longo do período 2016-2020. O desaparecimento de Mario não permitiu efetivar parte substantiva do potencial desse esforço sob a forma de textos, artigos, entrevistas e livros. Ainda assim, ao longo desse intervalo, vieram à luz alguns materiais que nos permitem vislumbrar os rumos que tomava o pensamento de Mario. ${ }^{5} \mathrm{O}$ marco inicial dessa produção é a organização que fizemos já no ano de 2016, do número 22 da Revista Verinotio, dedicado ao tema da (des)centralidade do trabalho.

Nos últimos meses de 2019, em uma tarde de estudos, na casa de Mario, conversávamos sobre como, na sociedade do capital, o trabalho vivo revive o trabalho morto presente em máquinas, equipamentos e matérias-primas. Nesse instante, ele me olha muito sério e diz algo assim: "Paulo, temos algo semelhante quando lemos autores que já não estão entre nós. As objetivações de suas ideias, de suas habilidades etc. retornam à vida quando os livros e textos desses autores são lidos, discutidos e criticados. De um certo modo, eles permanecem vivos conosco, em permanente diálogo". Jamais poderia imaginar que em pouco mais de um ano estaria escrevendo um texto em homenagem póstuma ao meu querido professor, coorientador, coautor, amigo, "irmão mais velho" e modelo de intelectual - rigoroso, generoso, incansável leitor e possuidor de uma cultura enciclopédica e de uma escrita exemplar. Ainda assim, tomo as palavras acima e convido a todas e todos interessados a ler, discutir e criticar os materiais de Mario. Não apenas o manteremos vivo, prestando a melhor homenagem possível a um intelectual que já não está entre nós como, certamente, encontraremos inúmeras sugestões, pistas e trilhas para a reconstrução do marxismo enquanto ciência e ideologia emancipadora do valor.

IV

Não poderia encerrar esse relato sem mencionar dois pontos: (1) Mario, ao longo de suas aulas nas turmas de graduação, de pós-graduação, nas atividades de extensão,

\footnotetext{
${ }^{5}$ Ao final desse escrito, listo alguns materiais produzidos por Mario que poderão dar uma ideia geral da produção teórica que ele desenvolveu ao longo de sua vida acadêmica.
} 
em seminários e grupos de estudo formou dezenas de professores, pesquisadores e lutadores sociais, todos profundamente comprometidos com a intelecção do ser social sob o domínio do capital. Há toda uma geração de marxistas em atuação hoje, no Brasil e no mundo, que se beneficiaram direta e indiretamente da reflexão teórica e da figuração de mundo que Mario constituiu ao longo de sua vida. Conforme nos lembra Eleutério Prado: "Se podemos falar de um marxismo de Niterói, pelo menos no âmbito da Economia, devemos isso à Mario Duayer". (2) Mario, juntamente com Nélio Schneider, traduziu, diretamente do alemão, os Grundrisse para a edição organizada pela Editora Boitempo, além de ter feito a Supervisão Editorial dessa edição. Além disso, Mario traduziu, com Carlos Nelson Coutinho e Nélio Schneider, o volume 1 de Para uma Ontologia do Ser Social, também publicada pela Editora Boitempo.

A seguir, apresento uma rápida relação de artigos e textos de Mario que podem ser do interesse dos leitores.

\section{Artigos publicados em periódicos:}

DUAYER, M. Anti-realismo e absolutas crenças relativas. Margem Esquerda, v. 8, pp. 109-130, 2006.

DUAYER, M. Antirrealismo e absolutas crenças relativas. Verinotio, Belo Horizonte, v. 14, pp. 16-27, 2012.

DUAYER, M.; ARAUJO, P. H. F. Desventuras do marxismo tradicional: notas sobre a polêmica Harvey-Roberts. Outubro (São Paulo), v. 34, pp. 63-88, 2020.

DUAYER, M.; ARAUJO, P. H. F. Para a crítica da centralidade do trabalho: contribuição com base em Lukács e Postone. Revista Em Pauta, v. 35, pp. 15-36, 2015.

DUAYER, M.; ARAUJO, P. H. F. Valor como forma de mediação social: interpretação de Marx a partir de Postone. Revista da Sociedade Brasileira de Economia Política, 2020.

DUAYER, M. Capital: More Human than Human (Blade Runner e a Barbárie do Capital). Revista Trabalho Necessário, Ano 8, n. 11, 2010.

DUAYER, M. Ceticismo e Desalento: relativismo ontológico em tempos de pós-verdade. Revista Sinais Sociais, 2020.

DUAYER, M. Concepção de História e Apostasias de Esquerda. Crítica Marxista, São Paulo, v. 22, pp. 109-131, 2006.

DUAYER, M. Desencanto Revolucionário, Ininteligibilidade da História e Apostasia de Esquerda: E. P. Thompson sobre L. Kolakowski. Esboços (UFSC), Florianópolis, SC, v. 12, pp. 75-95, 2004.

DUAYER, M. Dinossauros, Micos-Leões e Teoria Econômica. Pesquisa e Debate, São Paulo, v. 7, n.2, pp. 75-95, 1996.

DUAYER, M.; ESCURRA, MARÍA FERNANDA; SIQUEIRA, ANDREA VIEIRA. A ontologia de Lukács e a restauração da crítica ontológica em Marx. Revista Katálysis (Impresso), 
v. 16, p. 17-25, 2013.

DUAYER, M. Filosofía de la ciencia y crítica ontológica: verdad y emancipación. Herramienta, Buenos Aires, v. 55, pp. 95-113, 2014.

DUAYER, M.; GUMMET, P. The Brazilian Nuclear Power Industry: A Case Not Proven. ENERGY POLICY, pp. 323-325, 1981.

DUAYER, M. Jorge Luis Borges, filosofia da ciência e crítica ontológica: verdade e emancipação. Margem Esquerda, v. 24, pp. 87-110, 2015.

DUAYER, M. La ontología crítica de Lukács: para una ética objetivamente fundada. Herramienta Web, v. 2, p. 9, 2009.

DUAYER, M. Marx e a crítica ontológica da sociedade capitalista: crítica à centralidade do trabalho. Verinotio, Belo Horizonte, v. 22, pp. 29-43, 2016.

DUAYER, M. Marx e a crítica ontológica da sociedade capitalista: crítica do trabalho. Revista Em Pauta, v. 29, pp. 35-47, 2012.

DUAYER, M. Marx, Discurso e Verdade. Perspectiva (UFSC), Florianópolis, v. 19, n. 1, pp. 15-39, 2001.

DUAYER, M. MARX: el método de la economía política como crítica ontológica. Revista Eleuthera, v. 21, pp. 91-105-105, 2019.

DUAYER, M. Marx: 'O Método da Economia Política' Como Crítica Ontológica. Margem Esquerda, v. 33, pp. 99-114, 2019.

DUAYER, M.; MEDEIROS, J. L. G. Marx e a miséria brasileira: Considerações Psicografadas. Temporalis - Revista da ABEPSS, v. 6, 2003.

DUAYER, M.; MEDEIROS, J. L. G. Marx, estranhamento e emancipação: o caráter subordinado da categoria da exploração na análise marxiana da sociedade do capital. Revista de Economia (UFPR), v. 34, pp. 151-161, 2008.

DUAYER, M.; MEDEIROS, J. L. G. Miséria brasileira e macrofilantropia: psicografando Marx. Revista de Economia Contemporânea, Rio de Janeiro, v. 7, n. 2, 2003.

DUAYER, M.; MEDEIROS, J. L. G.; PAINCEIRA, J. P. A Miséria do Instrumentalismo na Tradição Neoclássica. Estudos Econômicos. Instituto de Pesquisas Econômicas, São Paulo, v. 31, n. 4, pp. 1-61, 2001.

DUAYER, M.; MEDEIROS, J. L. G. Produrre Miseria e Proporsi di Abolire la Povertà: Una Strana Missione del Capitalismo. Proteo (Roma), v. 2, pp. 414-432, 2005.

DUAYER, M.; MEDEIROS, João Leonardo. Lukács' Critical Ontology and Critical Realism. Journal of Critical Realism, Inglaterra, v. 4, n. 2, pp. 395-425, 2004.

DUAYER, M.; MORAES, Maria Célia Marcondes de. História, estórias: morte do real ou derrota do pensamento? Perspectiva, Florianópolis, v. 16, n. 31, pp. 51-68, 1998.

DUAYER, M.; MORAES, M. C. M. Neopragmatismo: a história como contingência absoluta. Tempo - Revista do Departamento de História da UFF, Rio de Janeiro, v. 4, pp. 27-48, 1997.

DUAYER, M.; MORAES, M. C. M. Recelebração do mercado: conservadorismo e crítica. Universidade e Sociedade (ANDES), v. IV, n.10, pp. 34-39, 1996.

DUAYER, M. Mercadoria e trabalho estranhado: Marx e a crítica do trabalho no capitalismo. Margem Esquerda, v. 17, pp. 88-99, 2011. 
DUAYER, M. Ontologia social organicista Pos-Keynesiana: ruptura com o neoclassicismo? ENSAIOS FEE, v. 16, n. 1, pp. 190-217, 1995.

DUAYER, M. Purgatório (curto conto teológico-metodológico). Revista da Sociedade Brasileira de Economia Política, Rio de Janeiro, v. 2, pp. 144-159, 1998.

DUAYER, M. Relativismo, certeza e conformismo: para uma crítica das filosofias da perenidade do capital. Revista da Sociedade Brasileira de Economia Política, v. 27, pp. 58-83, 2010.

DUAYER, M. Shackle: A tardia (e inútil) descoberta da teleologia pela ciência econômica. Ensaio, v. 17/18, n. especial, pp. 347-369, 1989.

\section{Livros publicados/organizados ou edições:}

DUAYER, M. György Lukács. Años de peregrinaje filosófico. v. 1, 1. ed. Buenos Aires: Ediciones Herramienta, 2013.

MULLER, R. (Org.); DUAYER, M. (Org.). A carta aberta de E. P. Thompson a L. Kolakowski e outros ensaios. 1. ed. Florianópolis: Em Debate/UFSC, 2019.

\section{Capítulos de livros publicados:}

DUAYER, M. Capital: a verdade absoluta do ceticismo pós-moderno e adjacências. In: OLIVEIRA, I. F. et al. (Org.). Marx hoje: pesquisa e transformação social. 1. ed. São Paulo: Outras Expressões, 2016, pp. 137-154.

DUAYER, M. Desencanto revolucionário, ininteligibilidade da história e apostasia de esquerda: E. P. Thompson sobre L. Kolakowski. In: Muller, R.; Duayer, M. (Org.). $A$ carta aberta de E. P. Thompson a L. Kolakowski e outros ensaios. 1. ed. Florianópolis: Em Debate/UFSC, 2019, v. 1, pp. 283-314.

DUAYER, M. Jorge Luis Borges, Filosofia da Ciência e Crítica Ontológica. In: TORRIGLIA, Patricia Laura; et al. (Org.). Ontologia e crítica do tempo presente. 1. ed. Florianópolis: Editoria Em Debate, 2015, pp. 51-78.

DUAYER, M. Marx e a crítica ontológica da sociedade capitalista: crítica do trabalho. In: VAISMAN, Ester; VEDDA, Miguel. (Org.). Lukács. estética e ontologia. 1. ed. São Paulo: Alameda, 2014, pp. 243-257.

DUAYER, M. Marx, estranhamento e emancipação: o caráter subordinado da categoria da exploração na análise marxiana da sociedade do capital. In: ALCÂNTARA, Norma; SOUZA, Reivan; FREIRE, Silene de Morais. (Org.). Reflexões em tempos de crise: trabalho, política movimentos sociais, serviço social. 1. ed. Maceió: Edufal, 2015, pp. 77-89.

DUAYER, M. Marx: the method of political economy as an ontological critique. In. OLIVA, Antonio; NOVARA, Ivan; OLIVA, Angel. (Org.). Marx and Contemporary Critical Theory. The Philosophy of Real Abstraction. 1. ed. London: Palgrave, 2020, pp. 214223.

DUAYER, M. Unlikely Affinities: J.L. Borges, Kuhn, Lakatos and Ontological Critique. In. Thompson, M. (Org.). Georg Lukács and the Possibility of Critical Social Ontology. 1. ed. London: Brill, 2019, pp. 267-288.

DUAYER, M. Mercancia y trabajo alienado: Marx y la crítica del trabajo en el capitalismo. In: DUAYER, M; VEDDA, M. (Org.). György Lukács. Años de peregrinaje filosófico. 1. ed. Buenos Aires: Ediciones Herramienta, 2013. 
DUAYER, M.; MEDEIROS, J. L. G. A Ontologia Crítica de Lukács: para uma ética objetivamente fundada. Irr. MIRANDA, F.F.; MONFARDINI, R. D. (Org.). Ontologia e estética, Coleção Niep-Marx, v. II. 1. ed. Rio de Janeiro: Consequência, 2015, v. II, pp. 17-44.

DUAYER, M.; MEDEIROS, João Leonardo. Under-labouring' for Ethics: Lukács' Critical Ontology. In: LAWSON, Clive; LATSIS, John; MARTINS, Nuno. (Org.). Contributions to Social Ontology. 1. ed. London: Routledge, 2007, pp. 102-123.

DUAYER, M.; MORAES, M. C. M. A Ética Pragmática do Neoconservadorismo: Richard Rorty. In: BORHEIM, Gerd. (Org.). Ética. Rio de Janeiro: UAPE, 1997, pp. 99-139.

\section{Referências bibliográficas}

ARAUJO, P. H. F. As categorias classes sociais e Estado no Livro Primeiro de O capital. Para que leiam O Capital: interpretações sobre o Livro 1, São Paulo: Usina Editorial, 2021, pp. 265-287

ARAUJO, P. H. F. Marx: Capital, Estado e política: notas. Revista da Sociedade Brasileira de Economia Política, v. 43, pp. 37-62, 2016.

CHASIN, J. Marx. Estatuto Ontológico e Resolução Metodológica, São Paulo: Boitempo, 2009.

DUAYER, M.; ARAUJO, P. H. F. Para a crítica da centralidade do trabalho: contribuições de Lukács e Postone. Revista Em Pauta, v. 13, pp. 15-36, 2015.

DUAYER, M.; ARAUJO, P. H. F. Trabalho abstrato, objetivação, alienação, fetiche - Marx lido por Postone. In: Anais do XXV Encontro Nacional de Economia Política, Salvador, 2020a. $<$ https://enep.sep.org.br/uploads/835 1583538394 Versão Final Identificada T rabalho Abstrato, Objetivação, Alienação, Fetiche Marx lido por Postone pdf ide.pdf> Acesso em:26/062021.

DUAYER, M.; ARAUJO, P. H. F. Valor como forma de mediação social: interpretação de Marx a partir de Postone. Revista da Sociedade Brasileira de Economia Política, v. 57, pp. 45-82, 2020b.

LUKÁCS, G. História e Consciência de Classe - Estudos sobre a dialética marxista, São Paulo: Martins Fontes, 2003.

LUKÁCS, G. Para uma ontologia do ser social. v. I, São Paulo: Boitempo, 2012.

LUKÁCS, G. Para uma ontologia do ser social. v. II, São Paulo: Boitempo, 2013.

MARX, K. H. Grundrisse: manuscritos econômicos de 1857-1858: esboços da crítica da economia política. São Paulo: Boitempo, $2011 \mathrm{~b}$.

MARX, K. H. O capital: crítica da economia política: livro 1: o processo de produção do capital. São Paulo: Boitempo, 2017.

POSTONE, Moishe. Tempo, trabalho e dominação social: uma reinterpretação da teoria crítica de Marx. São Paulo: Boitempo, 2014.

\section{Como citar:}

ARAUJO, Paulo Henrique Furtado de. Em memória de Mario Duayer. Verinotio, Rio das Ostras, v. 27, n. 1, pp. 428-441, jan./jun 2021. 